\title{
Leafhopper prefers vines with greater amounts of irrigation
}

\author{
Kent M. Daane a Larry E. Williams a Glenn Y. Yokota a Shawn A. Steffan
}

\begin{abstract}
To determine how irrigation influences variegated grape leafhopper biology and pest status, field studies were conducted in an experimental vineyard at the Kearney Agricultural Center. Results showed that increases in the amount of applied water were correlated to increases in leafhopper nymph density and size. Similarly, adult leafhoppers dispersed in greater numbers and had a higher reproductive potential on vigorously growing vines.
\end{abstract}

The variegated grape leafhopper, Erythroneura variabilis, is the most serious insect pest of grapevines in California's San Joaquin Valley. This leafhopper spread from Southern California and Mexico into the San Joaquin Valley in the late 1970 s and soon surpassed the grape leafhopper, Erythroneura elegantula, in pest status. At high densities, the variegated grape leafhopper can cause chlorotic spotting and defoliation, reducing leaf photosynthesis; and its excretions of honeydew act as a substrate for sooty molds, resulting in cosmetic damage to fruit. Adult leafhoppers flying at harvest time hinder workers and can limit their productivity.

Insecticides have been the main deterrent against this pest; however, their use is in jeopardy because of increasing pesticide resistance, secondary pest outbreaks of spider mites (Tetranychus pacificus and Eotetranychus willamettei) and regulatory restrictions. For these reasons, researchers are currently investigating methods to improve "biotic" controls by manipulating natural enemies through the addition of cover crops, parasite ref-

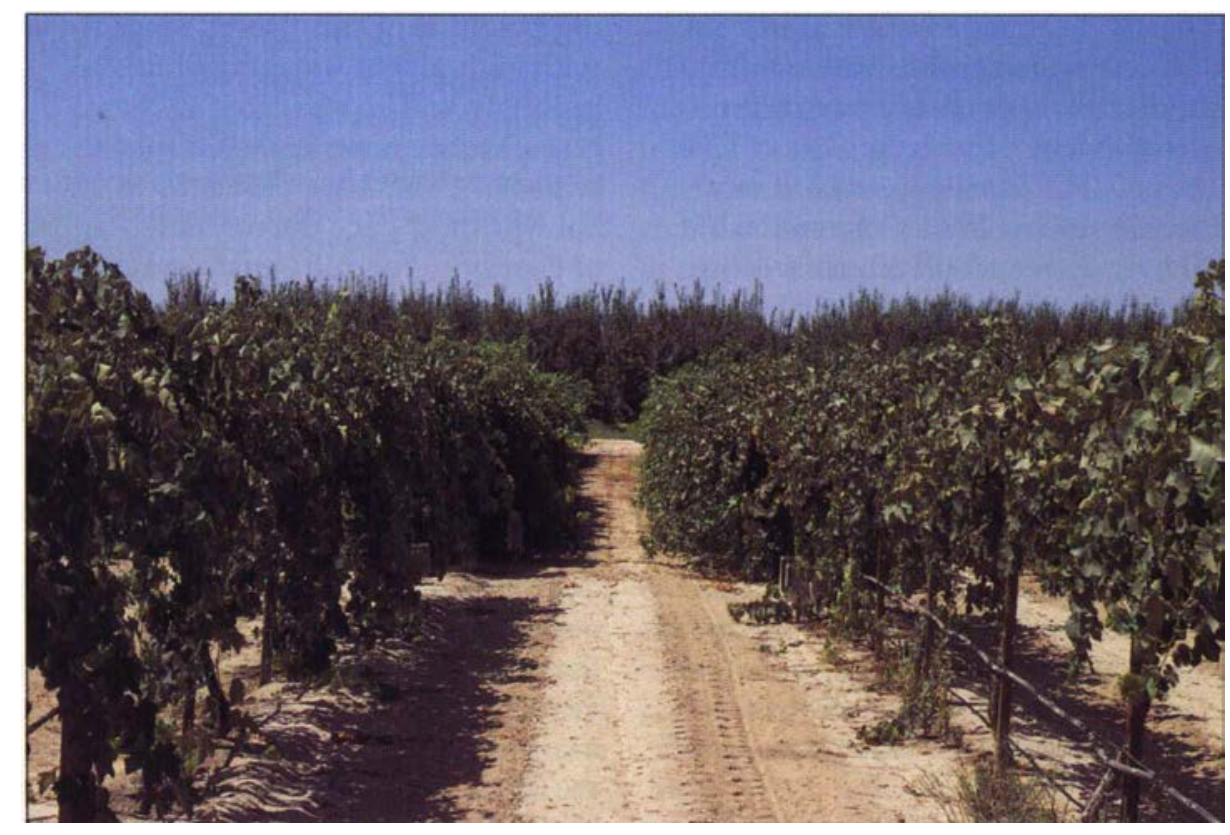

In this 'Thompson Seedless' vineyard, irrigation amounts ranged from 0 (vines in foreground) to 1.4 times (vines in back) the water amounts given to 2 vines in a weighing lysimeter. Irrigation amounts sequentially increased or decreased in adjacent rows, providing eight replicates of eight irrigation treatments.

uges and augmentative releases. Less attention has been given to "abiotic" controls, which include the effects of cultural practices such as irrigation, fertilization, canopy management and cultivar on leafhopper pest status.

A better understanding of insectplant interactions will benefit the development of integrated pest management programs. Previous work has correlated water-stressed vines to spider mite outbreaks, and vigorously growing vines to higher leafhopper densities (Grape Pest Management, DANR Publication No. 3343).

One important cultural practice that has a profound effect on vine vigor is the amount of applied water. Most vineyard irrigation studies have focused on the effects of water deficit on vegetative growth, yield and fruit quality. Less well understood are biological interactions between leafhoppers and grapevines that result from different irrigation amounts affecting leafhopper pest densities. To determine mechanisms by which irrigation amounts affect leafhoppers, a study was initiated in 1990 in a 3.2-acre (1.3hectare) 'Thompson Seedless' vineyard at the Kearney Agricultural Center. Vines in this vineyard were part of a long-term irrigation study using a weighing lysimeter to measure vine water use.

\section{Methods}

Study site. 'Thompson Seedless' vines used in this study were planted as cuttings in April 1987. Vine and row spacings were 7.4 feet by 11 feet $(2.25$ meters by 3.35 meters), respectively. 
Rows were planted in an east-west direction. Two cuttings were planted in a weighing lysimeter located close to the center of the vineyard.

The weighing lysimeter consisted of a large soil container with a surface area of 86 square feet ( 6.6 feet by 13.1 feet; 8 square meters, 2 meters by 4 meters) and an effective root depth of 6.6 feet ( 2 meters), resting on a sensitive scale. The scale's load cell was connected to a data logger. The overall system resolution was less than 1 pound (400 grams or 0.05 millimeters of water). The calibration accuracy of the lysimeter was \pm 0.001 inches $(0.025$ $\mathrm{mm}$ ) of water. The lysimeter was weighed hourly each day throughout the growing season. Weight loss was assumed to be due to the loss of water by grapevines via transpiration and from the soil via evaporation.

The two vines in the weighing lysimeter were automatically irrigated (via drip irrigation) whenever the vines used 0.08 inches $(2 \mathrm{~mm}$ ) of water. During the hottest parts of the growing season these vines may have been irrigated four or five times a day. Using data from 1993 as an example, the total applied water given to the vines in the lysimeter between initiation of irrigation (May 3) and harvest (September 21) amounted to 1,494 gallons $(5,647$ liters) per vine. Total evapotranspiration for those vines from budbreak (March 10) to harvest was 31.6 inches $(802 \mathrm{~mm})$ of water. Beginning with the third growing season, individual rows surrounding the lysimeter were irrigated (via drip) at various fractions of the amount of water used by the vines in the lysimeter. Irrigation treatments ranged from 0.0 to 1.4 (in 0.2 increments) times the water amounts given to the vines in the lysimeter, using the same daily frequency. Irrigation treatments were laid out in a line-source configuration (irrigation amounts sequentially increasing or decreasing in adjacent rows). Therefore blocks consisted of single rows of 18 vines each, with eight replicates of each treatment block.

Nymph density. Data on the effects of the irrigation treatments on leafhop- per population densities were collected in 1992. The density of leafhopper nymphs was determined for each brood in the $0.0,0.4,0.8$ and 1.2 irrigation treatments by counting the number of leafhoppers on 40 leaves in each of the treatment replicates (eight replicates, 320 leaves per treatment). Sample dates were timed to match peak leafhopper densities for each of the three leafhopper broods, based on weekly observations of leafhopper development.

Nymph mortality. To determine the influence of irrigation treatments on the mortality of leafhopper nymphs, we placed 10 first or second instar variegated leafhoppers on "clean" leaves (no other leafhopper nymphs), isolated by organdy cages. The $0.0,0.4,0.8$ and 1.2 irrigation treatments were tested, with five replicates per treatment, each in separate blocks. The tested leaves were mature, on leaf nodes four to eight. Cages were on the north side of the vine to minimize the effect of direct sunlight on temperatures inside the cages. Some leafhoppers died immediately after transfer. To account for this mortality, 3 days after the initial transfer we added second instar leafhoppers, bringing the total number to 10 leafhoppers per leaf. The experiment was undertaken concurrently with the second leafhopper brood (June 30 to July 30, 1993).

Nymph weight. The effect of irrigation treatments on leafhopper size was estimated by weighing individual nymphs. Approximately 300 fully developed fifth instar leafhoppers nymphs were collected at the end of the second brood (July 27, 1992) from each of four blocks in each irrigation treatment. The leafhoppers were immediately frozen and then oven-dried at $250^{\circ} \mathrm{F}$ for 1 hour. Nymphs were weighed, in groups of three, to the nearest microgram.

Adult movement. We studied the preference of adult leafhoppers to disperse to vines with different irrigation amounts. We collected approximately 30,000 adult leafhoppers from the 1.0 irrigation treatment with a D-Vac suction sampling machine. The leafhoppers were gassed with $\mathrm{CO}_{2}$, marked with a fluorescent dye and then released near the lysimeter plot at locations equidistant from each irrigation treatment level (three replicates, about 10,000 adults per block). One day after the release, treatment plots were again sampled with the D-Vac. (Collections were made in the afternoon, and each plot was sampled for a similar time period.) The samples were cleaned of 
plant debris and immature leafhoppers. In five subsamples, 500 adult leafhoppers were counted and weighed; the total number of leafhoppers collected in each treatment replicate was then estimated by sample weight. In each sample, we examined collected leafhoppers under an ultraviolet light and counted the number of marked and recaptured leafhoppers. The experiment was conducted on $\mathrm{Au}$ -

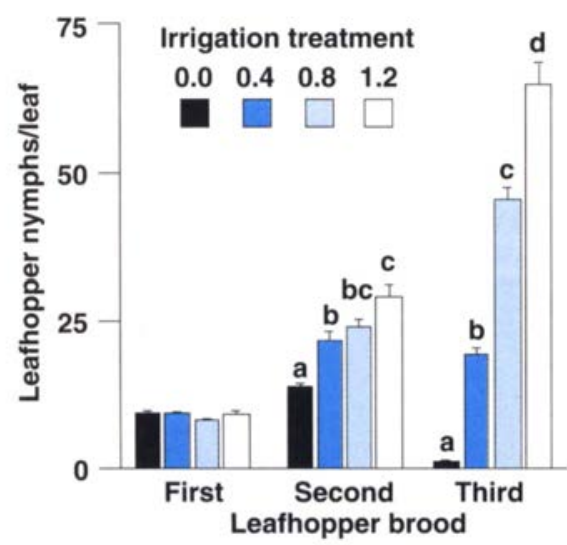

Fig. 1. Peak leafhopper nymph densities in 1992, in each of the three summer broods, show that differences in leathopper densities among irrigation treatments increased as the season progressed. The decrease in leafhopper numbers in the third brood in treatments with deficit irrigation (0.0 and 0.4 ) corresponds to a decline in vine condition in those treatments. Within each brood, treatment means separated by different letters are significantly different (Tukey's multiple comparison test, $P<0.05$ ).

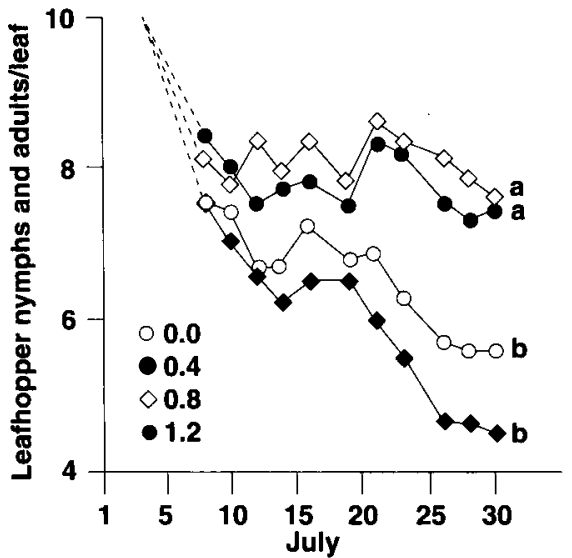

Fig. 2. Leafhopper nymph mortality was significantly greater in the deficit irrigation treatments $(0.0$ and 0.4$)$ than in treatments receiving adequate irrigation amounts $(0.8$ and 1.2), as measured by the number of nymphs surviving to the adult stage. Treatment means separated by different letters are significantly different (Tukey's multiple comparison test, $P<0.05$ ). gust 6 and 7,1993 , at the end of the second leafhopper brood.

Adult fecundity. The effect of irrigation treatments on adult fecundity was estimated from the number of eggs deposited by adult leafhoppers that were enclosed in organdy cages. Two experiments were conducted concurrently with the third leafhopper brood, August 1 to September 15, 1993.

In the first experiment, the tested adults were reared from nymphs that had been isolated in organdy cages in the 1.0 irrigation treatment. The cages were checked daily; newly molted adults were collected and sexed. Before collecting the tested adults, we set up organdy treatment cages that isolated three mature, clean leaves. Within hours after the tested adults were collected and sexed, five females and two or three males were placed in each cage. Treatments tested were the $0.0,0.6$ and 1.2 irrigation amounts, with four replicates, each in a separate treatment block.

In the second study, leafhopper nymphs were caged in the 0.0, 0.6 and 1.2 treatments. From these cages, adult leafhoppers were reared, collected and placed in organdy cages in the 1.0 irrigation treatment, as described above. After 4 weeks, when all adult leafhoppers had died, we counted the number of live, hatched and dead leafhopper eggs in all cages.

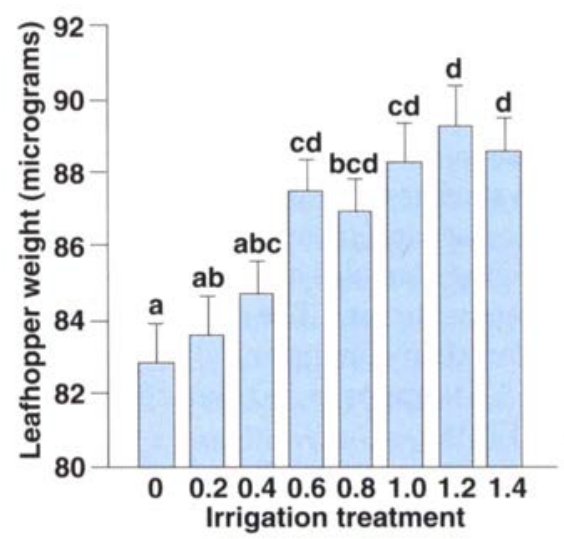

Fig. 3. The weight of fifth instar leafhoppers was significantly and positively correlated to irrigation levels $(y=83.12+4.65 x$, $\left.r^{2}=0.89, P<0.001\right)$. For statistical analysis, data points that were \pm 2.5 standard deviations from their respective treatmentblock means were discarded as outliers. Treatment means separated by different letters are significantly different (Tukey's multiple comparison test, $P<0.05$ ).

\section{Results of irrigations}

Vines irrigated at amounts equal to or greater than water applied to the vines in the lysimeter were never under stress at any time during the growing season, based on plant measures of vine water status (that is, photosynthesis, stomatal conductance and leaf water potential, and canopy temperature). However, these same measurements were much lower for vines irrigated at less than full vine evapotranspiration. Measurements of vegetative growth (fresh pruning weights) were a linear function of applied water over the range of treatments imposed. Therefore leaf area per vine was almost three to five times greater for non-deficit-irrigated vines compared to those receiving no water $(0.0$ treatment). Yields over the course of the study have been maximized at irrigation amounts between the 0.6 and 1.0 treatments. Maximum yield (which was obtained with the 0.6 treatment) in 1993 was 21.4 tons per acre (48 tonnes per hectare), while yield of the non-irrigated vines was 6.9 tons per acre (15.7 tonnes per hectare).

Nymph density. Our results agree with those of previous researchers, showing that leafhoppers prefer wellirrigated, vigorously growing vines. Additionally, our data show that the differential effect of irrigation treatments on leafhopper densities varies between leafhopper broods, becoming more evident with each successive leafhopper brood (fig. 1). In the first brood, no significant differences in leafhopper numbers were found among the four irrigation levels monitored. In the second brood, the number of leafhoppers per leaf was positively correlated to irrigation treatments. As the season progressed, increasing differences were noted among leafhopper population densities in the different irrigation treatments. Results from peak leafhopper counts in the third brood, taken in September, show an even stronger positive correlation between leafhopper numbers and irrigation levels, with significant differences in leafhopper densities among all irrigation treatments measured. The widening differences in leafhopper densities paralleled differences in vine water 
stress, discussed above. For example, winter rains provided an even amount of water to all irrigation treatments and resulted in adequate soil moisture early in the growing season; for this reason, measurements of vine water status did not indicate vine stress until the time of the second leafhopper brood, when differences in leafhopper numbers became apparent.

Nymph mortality. Significantly greater nymph mortality was recorded in the 0.0 and 0.4 irrigation treatment than in the 0.8 and 1.2 treatments, as measured by the number of leafhopper nymphs developing to the adult stage (fig. 2). The greatest reduction occurred during the early leafhopper stages and as the fifth instars molted to the adult stage.

It should be noted that this study tested the mortality of second to fifth instars. There may be a greater effect from host plant condition on leafhopper egg and first instar stages. Of the nymphs that reached the adult stage, their development was about 2 to 3 days faster in the 0.0 and 0.4 irrigation treatments. We believe that this difference can largely be explained by differences in vine temperature among the irrigation treatments. Canopy temperatures of the deficit irrigated grapevines were higher than ambient temperatures throughout the day by as much as $11^{\circ} \mathrm{F}\left(6^{\circ} \mathrm{C}\right)$. Grapevines that were irrigated at full evapotranspiration had canopy temperatures less than ambient and were up to $18^{\circ} \mathrm{F}\left(10^{\circ} \mathrm{C}\right)$ cooler than the deficit irrigated vines.

Nymph weight. Fifth instar weights, which are a reflection of size and feeding potential, show a significant and positive correlation between leafhopper weight and irrigation levels (fig. 3). It is not known from this study if larger nymphs, from wellirrigated vines, cause greater injury. We speculate that host plant compensation for leafhopper feeding is greater in well-irrigated than in deficitirrigated vines. Thus, a density of 20 leafhoppers per leaf causes more vine damage in the 0.2 than in the 1.2 irrigation treatment, regardless of increased leafhopper size and feeding at the higher irrigation level.

Adult movement. Significantly more adult leafhoppers were collected

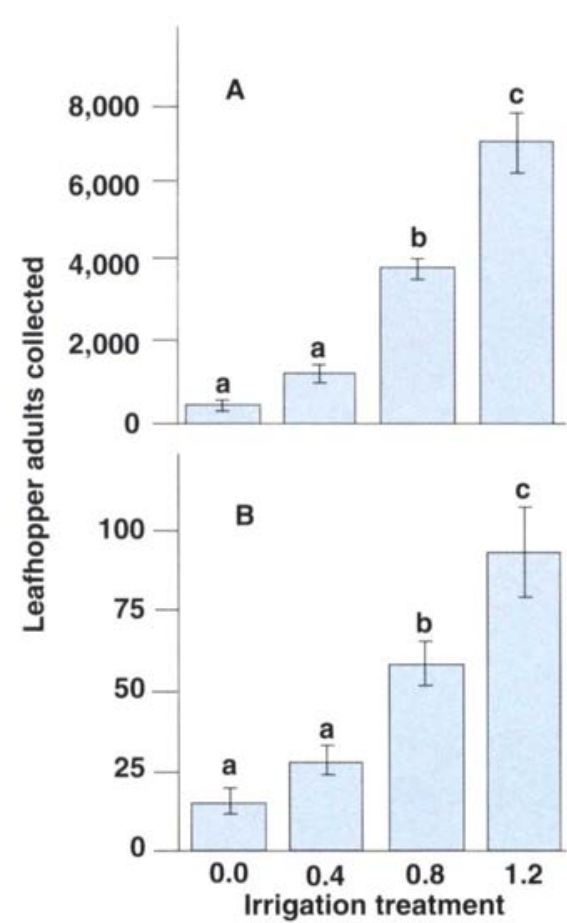

Fig. 4. The total number of adult leafhoppers $(A)$ and the number of marked, released, and recaptured leafhoppers (B) were significantly and positively correlated to irrigation treatment levels, indicating that leafhopper adults are more attracted to or better retained on well-irrigated vines as compared to deficit-irrigated vines (total leafhoppers: $y=-191.7+5488.7 x, r^{2}=0.87, P<0.001$; dyed leafhoppers: $y=9.12+66.25 x, r^{2}=$ $0.76, P<0.001$ ). Treatment means separated by different letters are significantly different (Tukey's multiple comparison test, $P<0.05$ ).

in the higher irrigation treatment levels as compared with adults collected in treatment levels below 0.6 , the level of maximum grape yield in 1993 (fig. 4A). The recapture of marked adults also found a significant and positive correlation between adult leafhoppers and irrigation levels (fig. 4B). The results imply that the adult leafhoppers were either more attracted to vines in the higher irrigation treatments or that they randomly dispersed but were better arrested at the higher irrigation treatments.

Adult fecundity. The reproductive potential of leafhoppers is an important part of leafhopper biology and pest status. Results from the leafhopper egg deposition test show that significantly more eggs were deposited on leaves in the 1.2 irrigation treatment than on leaves without irrigation (fig. 5A), indicating that severely

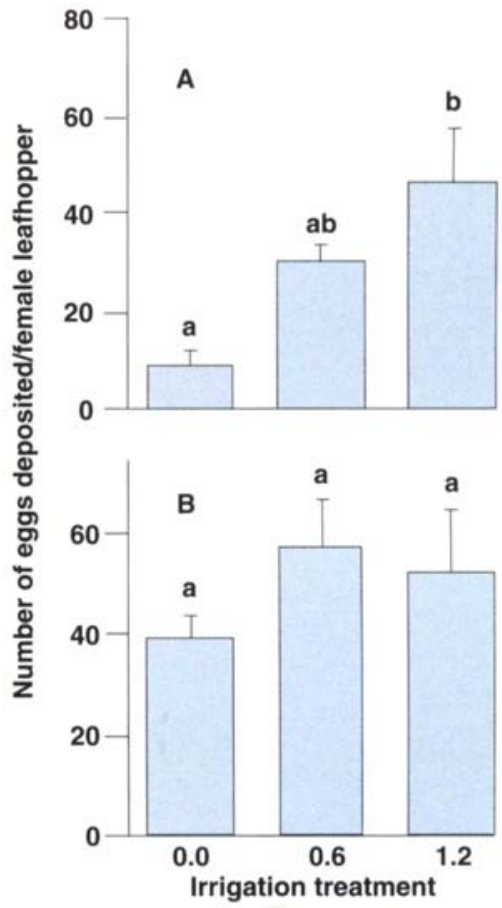

Fig. 5 (A) The number of eggs deposited per adult female (derived from nymphs reared in the 1.0 treatment) was significantly less in the 0.0 than in the 1.2 irrigation treatment, indicating that severe deficit irrigation can affect egg deposition. (B) There was no significant difference among treatments in the number of eggs deposited per female (derived from nymphs reared in the $0.0,0.6$ and 1.2 treatments) in the 1.0 treatment, indicating that adult leafhoppers can compensate for poor food quality provided to nymphs. Treatment means separated by different letters are significantly different (Tukey's multiple comparison test, $P<0.05$ ).

water-stressed leaves either were a poorer adult food source or created a less favorable environment. This could have resulted in either lower adult fecundity (total egg production) or shorter adult longevity, both of which would lower egg deposition. There were no significant differences in egg production in the cross-experiment, in which leafhopper adults were reared from nymphs on vines in the $0.0,0.6$ and 1.2 irrigation treatments and then were placed on leaves in the 1.0 irrigation level (fig. 5B). This implies that egg production by adult leafhoppers feeding on well-irrigated vines was not related to prior nymphal development on deficit-irrigated vines.

Previous researchers have documented the migration of overwintering adult leafhoppers into vineyards in the spring, and have found that the reproductive organs of overwintered 


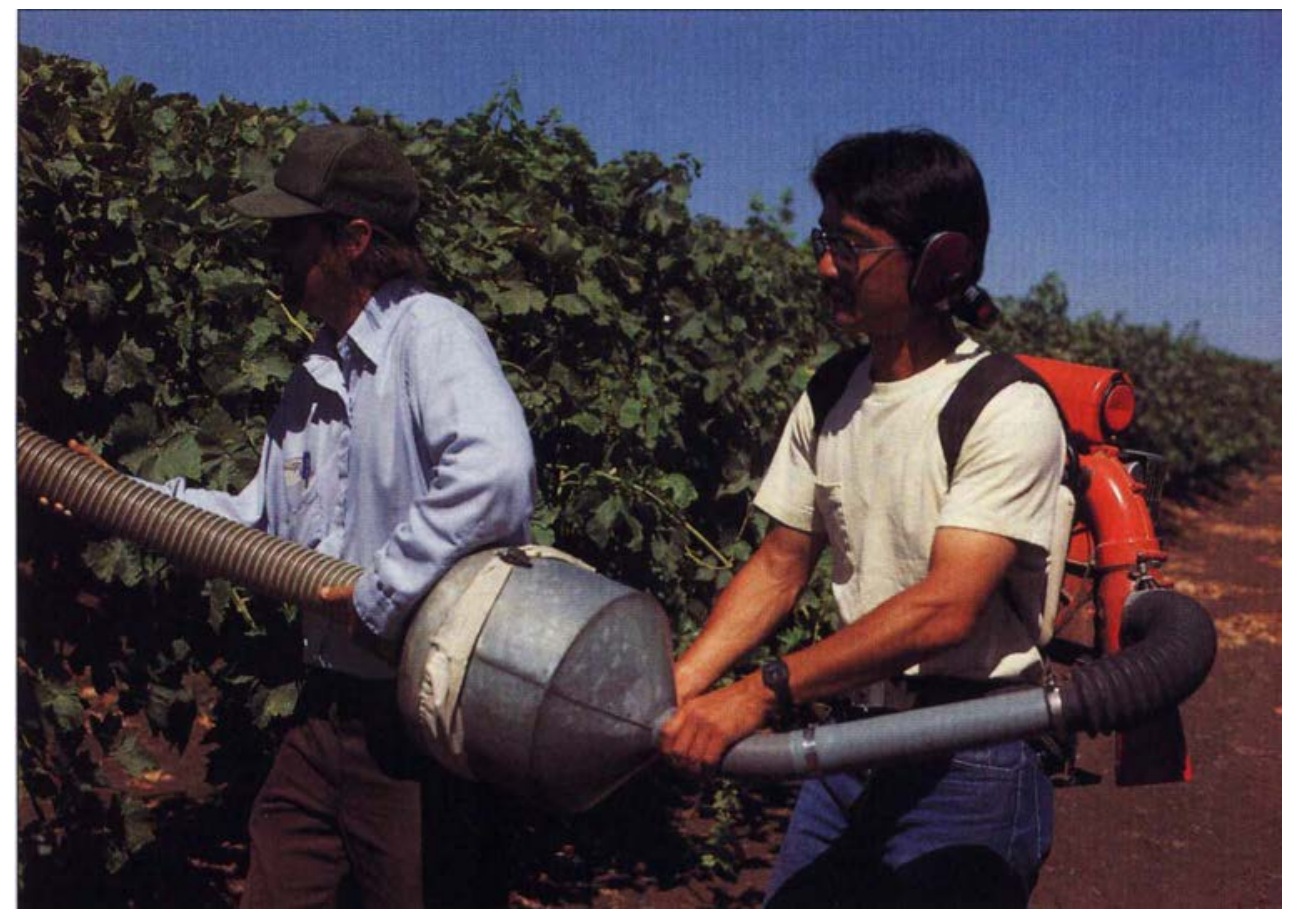

Adult leafhoppers were collected with a D-Vac vacuum, marked with a fluorescent dye, then released near the lysimeter block. Results showed that recapture of marked leafhoppers was positively correlated with irrigation amounts.

females do not produce eggs until the adults feed on grape leaves. However, there is little information on adult leafhopper movement or reproductive potential during the growing season. The results of our tests show that food quality, in this case as affected by irrigation amounts, can have an impact on "in-season" adult leafhopper movement and reproductive potential, which can greatly affect pest management. For example, adult leafhopper dispersal patterns would favor movement to vineyards with vigorously growing vines, on which adults will deposit more eggs as compared to adults feeding on vines with deficit irrigation levels; both migration and fecundity can increase or decrease the number of leafhopper nymphs in the next brood. Because of the small plot size and close proximity between plots in this study, the data cannot be interpreted to present information on adult movement between vineyards, only that there is significant movement in a vineyard among vines with different irrigation amounts. For example, we do not know at what point there is migration out of a heavily infested and damaged vineyard and into a clean vineyard. higher adult fecundity would produce more eggs that may survive.

The manipulation of vineyard cultural practices for pest management is not new; however, caution must be advised before undertaking irrigation management for leafhopper control. We are currently studying cultural practices that affect irrigation amounts without negatively affecting crop yield, management practices or secondary pests. This includes work with cover-cropping systems that have been associated with an increase in beneficial insects on the vineyard floor. Studies have shown that cover crops compete with vines for water and nutrients and therefore can reduce vine vigor. For this reason we speculate that cover crops can play a dual role in the management of leafhoppers.

Growers using cover-cropping systems to increase the number of beneficial insects may also reduce leafhopper numbers by reducing the amount of water available to the vines. Viticulturists have found the slight reduction in irrigation amounts and competition for soil nutrients associated with a well-managed cover crop does not noticeably affect crop yield. The possibility of using this information to improve leafhopper control exists; however, better information on leafhopper biology and host-plant tolerance to leafhopper damage is needed. It should also be noted that because irrigation amounts are related to vegetative growth, leaf nitrogen, vine temperature and many other physical and biological factors, tests on leafhopper density and biology could be correlated to these factors as well.

K.M. Daane is Associate Specialist, Laboratory of Biological Control, UC Berkeley; L.E. Williams is Professor, Department of Enology and Viticulture, UC Davis; G.Y. Yokota is Staff Research Associate, Laboratory of Biological Control, UC Berkeley; and S.A. Steffan is a graduate student in the Department of Entomology, University of Wisconsin. We thank Gunner Fossen, Dean Greenwood, Matt Jones, Ross Jones and Yvonne Rasmussen for laboratory and field assistance. Research funding was provided by the California Table Grape Commission and the California Raisin Advisory Board. 